\title{
Isolated short femur alone in the mid-trimester fetus is not associated with increased risk of aneuploidy: a clinical study in eastern India
}

\author{
Kalyansree Chaudhury $^{1}$, Kanchan Mukherjee ${ }^{2}$
}

\author{
${ }^{1}$ Department of Obstetrics \& Gynaecology, Burdwan Medical College, Burdwan, India \\ ${ }^{2}$ Remedy Medical Services, Kolkata, India
}

Received: 17 February 2016

Accepted: 12 March 2016

\author{
*Correspondence: \\ Dr. Kalyansree Chaudhury, \\ E-mail: kalyansree@yahoo.com
}

Copyright: (C) the author(s), publisher and licensee Medip Academy. This is an open-access article distributed under the terms of the Creative Commons Attribution Non-Commercial License, which permits unrestricted non-commercial use, distribution, and reproduction in any medium, provided the original work is properly cited.

\begin{abstract}
Background: Identifying the soft markers during the anomaly scan improves the detection rate of fetal aneuploidy at the cost of increased false-positive rate and consequent increased interventions. Isolated short femur is one such soft marker that puts the clinician into a dilemma. The aim of this study is to assess the risk of aneuploidy in the fetus with isolated short femur, so that the data can be used for counseling the prospective parents in our population.

Methods: In this retrospective study, all the fetuses of 43 mothers, at the time of ultrasound scan between 18-20 weeks of gestation for fetal anomaly, were found to have isolated short femur. Depending on the presence of other soft markers, the mothers were divided into two groups, group I containing mothers having fetus with only isolated short femur and group II containing mothers having fetus with one or more soft marker in addition to isolated short femur. The chromosomal status of all the fetuses was checked by either amniocentesis and karyotyping or birth of a phenotypically normal baby.
\end{abstract}

Results: There was no aneuploidy in the group I containing fetuses with isolated short femur only. Our results are consistent with other international studies.

Conclusions: Isolated short femur alone does not increase the existing risk of fetal aneuploidy.

Keywords: Soft marker, Isolated short femur, Fetal aneuploidy

\section{INTRODUCTION}

A soft marker is an ultrasound finding in the fetus, seen during the mid-trimester anomaly scan, which is nonspecific, also present in fetuses without abnormalities and is often transient and resolving by third trimester of gestation. ${ }^{1,2}$ These findings are distinct from fetal malformation. The presence of soft markers increases the risk of fetal aneuploidy, but is not diagnostic. ${ }^{3}$ Short femur is one such soft marker that is usually looked for during the midtrimester fetal anomaly scan. Including the soft markers during the anomaly scan definitely improves the detection rate of fetal aneuploidy though at the cost of increased false positive rate and consequent increased interventions. $^{4}$
A short femur was defined as a femur length (FL) $<5^{\text {th }}$ centile for gestational age. ${ }^{5}$ Isolated short femur (ISF) was diagnosed when the fetus had a short femur but normal abdominal circumference $(\mathrm{AC})\left(>5^{\text {th }}\right.$ centile) and estimated fetal weight $(\mathrm{EFW})\left(>5^{\text {th }}\right.$ centile) for gestational age., ${ }^{6,7}$ Early-onset intrauterine growth retardation was defined when $\mathrm{EFW}$ or $\mathrm{AC}<5^{\text {th }}$ centile at the mid-trimester ultrasound scan. ${ }^{8}$

Finding an isolated short femur at the time of midtrimester scan poses a challenge to the clinician: is there any fetal aneuploidy or is it a part of skeletal dysplasia or is it a normal variation? ${ }^{9}$ There are studies which have shown that short femur is associated with increased risk of subsequent intrauterine growth retardation in pregnancy and small for gestational age neonates. ${ }^{9-11}$ 
Hence, discussing the implications of the finding with the prospective parents is difficult.

In this study we have presented our experience about isolated short femur in our population. The aim of this study is to assess the risk of aneuploidy in the fetus with isolated short femur and to use this data in counselling the parents-to-be.

\section{METHODS}

In this retrospective study the fetal outcome of 43 mothers, whose fetuses had isolated short femur at the time of mid-trimester ultrasound scan at a private diagnostic clinic in Kolkata between March 2009 and January 2014, was reviewed. Local ethics committee approval was obtained and all patients had given informed consent.

During this study period, we found 77 mothers who, at the time of ultrasound scan for fetal anomaly between 1820 weeks of gestation, had singleton live fetus with short femur length. Mothers with multiple pregnancies and congenital malformation of the fetus were excluded from this study. Of these mothers, 3 mothers had fetus with AC $<5^{\text {th }}$ centile as well as short femur and hence were excluded from the study.

Of the remaining 74 mothers who had fetus with isolated short femur, one had miscarriage, 2 had stillbirths and 28 were lost in the follow up. All these 31 mothers, who had fetus with isolated short femur and no other soft marker, were excluded from this study as their fetal chromosomal data were not available. Only the remaining 43 mothers, whose fetal chromosomal status was known, were included in the study. A thorough evaluation of fetal biometry and systematic fetal anatomy scan including a panel of 6 soft markers (nuchal thickening, hyperechoic bowel, shortened femur or humerus, echogenic intracardiac focus and renal pyelectasis) was performed on each mother.

Depending on the number of soft markers present in the fetus, the mothers were divided into two groups. One group (Group I) contained 29 mothers with fetus having isolated short femur only and no other soft marker. The other group (Group II) contained 14 mothers with fetus having isolated short femur and at least another soft marker or more. All the mothers of group II had amniocentesis and fetal karyotyping. Two mothers of group I also had amniocentesis and karyotyping. The fetal chromosomal status of all the mothers was confirmed either by birth of a phenotypically normal baby or by karyotyping following amniocentesis.

All the babies, who were assessed by the paediatrician at birth and considered phenotypically normal, were regarded as euploid. Continuous variables in the two groups were compared using ' $t$ ' test. The significance level was set at $\mathrm{p}<0.05$.
Relevant maternal history and ultrasound findings were recorded at the time of ultrasound scan. Pregnancy outcome data were recorded at the database subsequently as it became available from the patients in the follow up or by direct questionnaire. All ultrasound scans were done by one of the authors (KM) trained in fetal medicine.

\section{RESULTS}

In this retrospective study we reviewed the fetal outcome of 43 mothers who had singleton live pregnancy, normal fetal anatomy and isolated short fetal femur at the time of fetal anomaly scan between 18-20 weeks of gestation. The overall mean age of the mothers was 30.92 years. The overall mean gestational age at the time of diagnosis of isolated short femur was 127.34 days (i.e. 18 weeks 1 day). There was no significant difference in the maternal age or gestational age between group I and group II.

Pregnancy characteristics of the participating women are given below.

Table 1: Demographic variables.

\begin{tabular}{|lllll|}
\hline \multicolumn{1}{|c|}{} & $\begin{array}{l}\text { Group I } \\
(\mathrm{n}=29) \\
\text { Mean } \\
\pm \text { SD }\end{array}$ & $\begin{array}{l}\text { Group II } \\
(\mathrm{n}=14) \\
\text { Mean } \pm \\
\text { SD }\end{array}$ & $\begin{array}{l}\text { p } \\
\text { value }\end{array}$ & Remarks \\
\hline $\begin{array}{l}\text { Maternal age } \\
\text { (in years) }\end{array}$ & $31.34 \pm$ & $30.28 \pm$ & $>0.05$ & N.S \\
\hline $\begin{array}{l}\text { Gestational } \\
\text { age } \\
\text { (in days) }\end{array}$ & 128.44 & $126.21 \pm$ & $>0.05$ & N.S \\
$\begin{array}{l}\text { (at the time } \\
\text { of diagnosis } \\
\text { of isolated } \\
\text { short femur) }\end{array}$ & \pm 4.33 & 2.93 & & \\
\hline
\end{tabular}

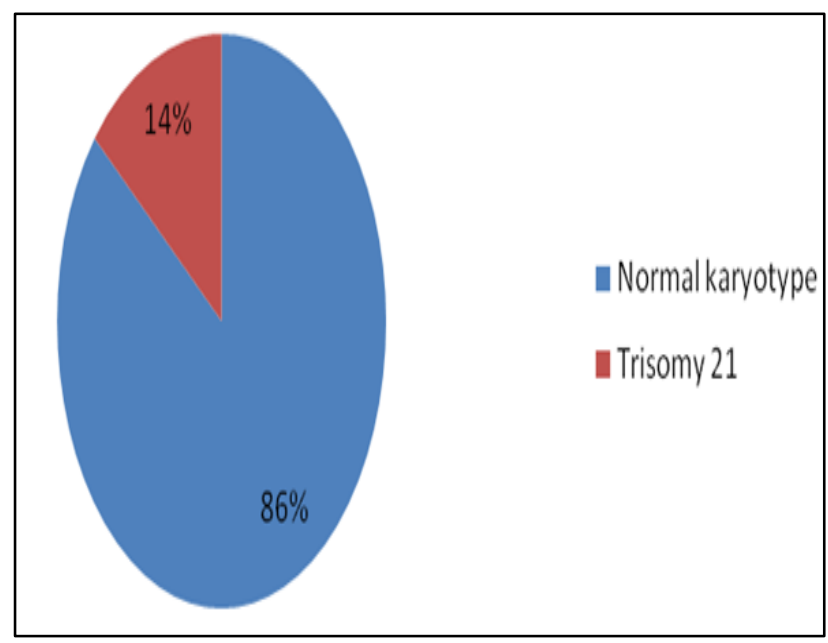

Figure 1: the chromosomal status in fetuses with 2 or more soft markers. 
Table 2: The summary of chromosomal status of all the babies.

\begin{tabular}{|c|c|c|c|c|}
\hline \multirow{2}{*}{$\begin{array}{l}\text { Total } \\
\text { number of } \\
\text { fetuses }(n= \\
43 \text { ) }\end{array}$} & \multicolumn{2}{|c|}{$\begin{array}{l}\text { Total number of } \\
\text { mothers }(n=43)\end{array}$} & \multirow{2}{*}{ palue } & \multirow{2}{*}{ Remarks } \\
\hline & $\begin{array}{l}\text { Group I } \\
(\mathrm{n}=29)\end{array}$ & $\begin{array}{l}\text { Group II } \\
(\mathrm{n}=14)\end{array}$ & & \\
\hline $\begin{array}{l}\text { Normal } \\
\text { fetus } \\
(n=41)\end{array}$ & 29 & 12 & & \\
\hline $\begin{array}{l}\text { Trisomy } \\
21 \\
(n=2)\end{array}$ & 0 & 2 & $>0.001$ & $\begin{array}{l}\text { Highly } \\
\text { significant }\end{array}$ \\
\hline
\end{tabular}

\section{DISCUSSION}

Definitive diagnosis of Down syndrome (DS), the commonest cause of mental retardation, can be made, at the moment, by invasive tests only such as amniocentesis, chorionic villus sampling etc. These invasive tests have serious shortcomings including miscarriage and cost implications. Hence, these tests cannot be applied to the whole pregnant population. Various screening tests, such as nuchal translucency thickness and blood biochemistry, were developed to optimize the amniocentesis rate for maximum detection of DS with minimum complications. However, these screening tests, either are not availed by many in our country or even if done, do not pick up all the DS fetuses.

Mid-trimester ultrasound scan (also called 'anomaly scan') is one of the most common genetic screening tests and diagnostic tests used during pregnancy. Apart from diagnosing structural malformations in the fetus which are important regardless of fetal chromosomal status, anomaly scan is useful in screening for chromosomal abnormalities by either detecting structural malformations which are associated with large number of fetal aneuploidies or by identifying 'soft markers' when the fetal aneuploidy is not associated with obvious structural defects.

In our study, there is no fetal aneuploidy when isolated short femur is the lone soft marker present in the fetus. This fact underpins the claim that isolated short femur, by itself, does not increase the risk of fetal aneuploidy. However, when the number of soft markers is more, the risk of fetal aneuploidy increases. Our study result is consistent with the results obtained in other international studies.

Vergani et al did not find any difference in the frequency of ISF between euploid and aneuploid fetuses. ${ }^{12}$ Similarly, Bromley et al found no difference, at the time of midtrimester scan, in the incidence of ISF between DS fetuses and control fetuses, when structural malformation of the fetus was excluded. ${ }^{2}$ Todros et al also did not find any chromosomal anomaly in a fetus with ISF but without structural malformation. ${ }^{9}$ In a large study Nyberg noted that the association of short femur, when present as a lone soft marker, with trisomy 21 did not reach statistical significance and the risk is very low (likelihood ratio 1.5). ${ }^{1}$ Morales-Rosello also noted that taking into account the invasive procedure risk, an isolated short femur should not be considered an indication for fetal karyotype. $^{13}$

Studies have confirmed that fetuses of asian mothers have shorter femurs and those of black mothers have longer femurs compared with fetuses of white mothers. ${ }^{14}$ However, these ethnic differences were not confirmed by the study of Weisz et $\mathrm{al}^{8}$, and it is possible that other factors, such as maternal and paternal height, are more important than ethnicity alone in influencing fetal femur length. ${ }^{15,16}$

In summary, isolated short femur, when present as lone soft marker, does not increase the background risk of fetal aneuploidy. Hence ISF, per se, is not an indication of fetal karyotype unless warranted by already existing background risk. However, the counselling of the prospective parents should emphasize that soft marker, such as ISF, assessment is a risk assessment and not diagnostic. We conclude that ISF, at the time of midtrimester anomaly scan, does not increase the existing background risk of fetal aneuploidy for that mother significantly.

\section{ACKNOWLEDGEMENTS}

We sincerely thank Dr. Shyamsundar Mandal, Statistical officer of Chittaranjan National Cancer Institute, for his help in statistical analysis of the data.

\section{Funding: Not required \\ Conflict of interest: None declared}

Ethical approval: The study was approved by the Institutional Ethics Committee

\section{REFERENCES}

1. Nyberg DA, Souter VL, El-Bastawissi A, Scott Y, Luthhardt F, Luthy DA. Isolated Sonographic Markers for Detection of Fetal Down Syndrome in the Second Trimester of Pregnancy. J Ultrasound Med. 2001;20:1053-63.

2. Bromley B, Lieberman E, Shipp TD, Benacerraf BR. The Genetic Sonogram: a method of risk assessment for Down syndrome in the second trimester. J Ultrasound Med. 2002;21:1087-96.

3. Van den Hof MC, Wilson RD et al. Fetal Soft Markers in Obstetric Ultrasound. J Obstet Gynaecol Can. 2005;27(6):592-612.

4. Todros T, Capuzzo E, Gaglioti P. Prenatal diagnosis of congenital anomalies. Images Paediatr Cardiol. 2001;3(2):3-18.

5. Chitty LS, Altman DG, Henderson A, Campbell S. Charts of fetal size: 4. Femur length. Br J Obstet Gynaecol. 1994;101:132-5. 
6. Chitty LS, Altman DG, Henderson A, Campbell S. Charts of fetal size: 3. Abdominal measurements. $\mathrm{Br}$ J Obstet Gynaecol. 1994;101:125-31.

7. Hadlock FP, Harrist RB, Sharman RS, Deter RL, Park SK. Estimation of fetal weight with the use of head, body and femur measurements - a prospective study. Am J Obstet Gynecol. 1985;151:333-7.

8. Weisz B, David AL, Chitty L, Peebles D, Pandya P, Patel P, et al. Association of isolated short femur in the mid-trimester fetus with perinatal outcome. Ultrasound Obstet Gynecol. 2008;31:512-6.

9. Todros T, Massarenti I, Gaglioti P, Biolcati M, Botta $\mathrm{G}$, Felice CD. Fetal short femur length in the second trimester and the outcome of pregnancy. BJOG. 2004;111:83-5.

10. Todros T, Plazzotta C, Pastorin L. Body proportionality of the small-for-date fetus: is it related to aetiological factors? Early Human Dev. 1996;45:1-9.

11. Zalel Y, Lehavi O, Schiff E et al. Shortened fetal long bones: a possible in utero manifestation of placental function. Prenat Diagn. 2002;22:553-7.
12. Vergani P, Locatelli A, Piccoli MG. Critical reappraisal of the utility of sonographic fetal femur. length in the prediction of trisomy 21. Prenat Diagn 2000;20:210-4.

13. Morales-Rosello $\mathrm{J}$ and LLorens NP. Outcome of Fetuses with Diagnosis of Isolated Short Femur in the Second Half of Pregnancy. ISRN Obstetrics and Gynecology. 2012:1-5.

14. Shipp TD, Bromley B, Mascola M, Benacerraf B. Variation in fetal femur length with respect to maternal race. J Ultrasound Med. 2001;20:141-4.

15. Kovac CM, Brown JA, Apodaca CC, Napolitano PG, Pierce B, Patience T, Hume RF Jr, Calhoun BC. Maternal ethnicity and variation of fetal femur length calculations when screening for Down syndrome. J Ultrasound Med. 2002;21:719-22.

16. Drooger JC, Troe JW, Borsboom GJ, Hofman A, Mackenbach JP, Moll HA, et al. Ethnic differences in prenatal growth and the association with maternal and fetal characteristics. Ultrasound Obstet Gynecol. 2005;26:115-22.

Cite this article as: Chaudhury $\mathrm{K}$, Mukherjee $\mathrm{K}$. Isolated short femur alone in the mid-trimester fetus is not associated with increased risk of aneuploidy: a clinical study in eastern India. Int J Reprod Contracept Obstet Gynecol 2016;5:1207-10. 